\title{
ARTIGOS
}

\section{PRODUÇÃO E USO DE DEQUES \\ MODULARES DE BAMBU E MADEIRA}

\section{PRODUCTION AND USE OF BAMBOO AND WOOD MODULAR DECKS}

\author{
FABIANO OSTAPIV, Dr. | UTFPR \\ CELSO SALAMON, Dr.|UTFPR
}

\begin{abstract}
RESUMO
Este trabalho mostra a produção manual de ripas de bambu a partir de colmos de Dendrocalamus asper, usando ferramentas e procedimentos simples. As ripas de bambu foram produzidas por faqueamento e usadas, junto com ripas comerciais de madeira de araucária, para construir deques modulares quadrados de 40 por $40 \mathrm{~cm}$. Estes deques podem ser utilizados de modos diferentes para montar móveis, portas, janelas, paredes, divisórias, forros e pisos. Foi feita a análise de tempos e movimentos produtivos para a produção de 40 deques modulares de bambu e madeira. Para a produção dos lotes foram usadas 160 ripas de bambu extraídas da base dos colmos de bambu e outras 160 ripas retiradas da região do meio dos colmos. Verificou-se que o tempo para a produção manual de ripas de bambu da região da base é do colmo é em média, 27\% maior que o tempo para obtenção de ripas da região do meio do colmo. Por fim, foi feita uma sugestão de um arranjo produtivo para a fabricação seriada dos deques modulares de bambu e madeira.
\end{abstract}

PALAVRAS CHAVE: Produtos modulares; Bambu e madeira; Cronoanálise

\begin{abstract}
This paper shows the manual production of bamboo slats from Dendrocalamus asper culms, using simple tools and procedures. Using the slatted bamboo together with commercial slats of araucaria wood, is possible assembly modular and standardized decks of 40 by $40 \mathrm{~cm}$. These decks can be used in several types of products, such as furniture, doors, windows, walls, partitions, ceilings and floors. The chronoanalysis of the production of 40 of these modular decks of bamboo and wood was made. For the production of the lot were used 160 bamboo slats obtained from the base of the bamboo culms and other 160 slats of the medium of the culms. The time to manual produce bamboo slats from the base region of the culm is, on average, $27 \%$ higher than to obtaining slats from the middle region. Finally, was made a suggestion to a productive arrangement for the serial manufacture of modular decks of bamboo and wood.
\end{abstract}

KEY WORDS: Modular products; Bamboo and wood; Chrono analysis 


\section{INTRODUÇÃO}

A área de bambu plantada e o uso do bambu no mundo tem crescido ano após ano. No Brasil esta tendência também é percebida. Cada vez mais as pessoas querem usar e construir com bambu. Esta planta têm um enorme potencial como material de engenharia e é particularmente muito útil na construção civil, Ostapiv (2017).

Um dos usos mais comuns do bambu atualmente no Brasil, é a construção de galpões e estufas para o meio rural, Silva et al (2011), alguns exemplos são mostrados nas Figuras 1 e 2.

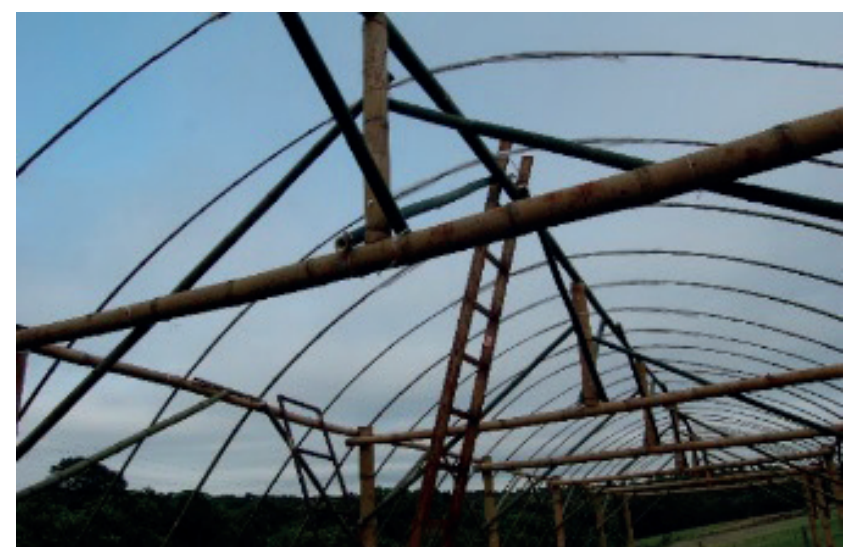

Figura 1: Estufa de D. asper e P. aurea, modelo CPRA, sendo construída no IAPAR-Pato Branco, (2016). Fonte: Elaborado pelo autor

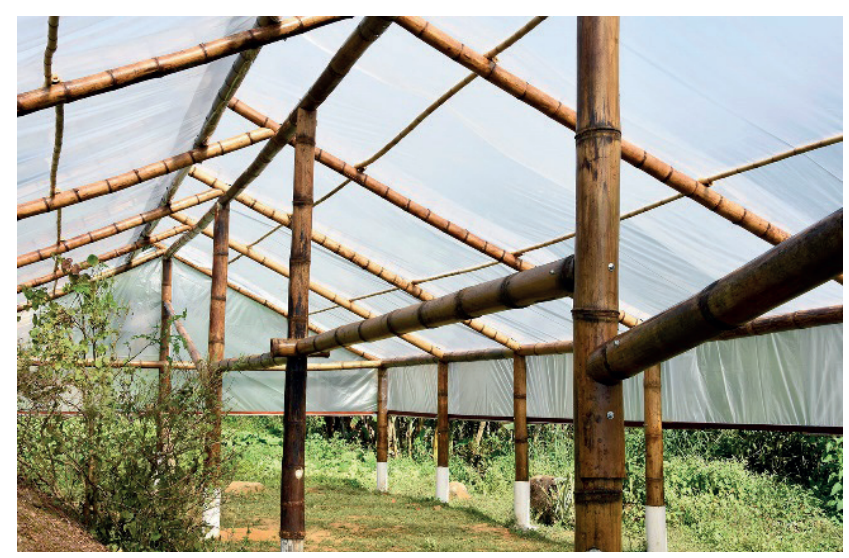

Figura 2: Estufa de D. asper e Guadua angustifólia na comunidade Hare Krsna de Goura Vrindavana, Paraty- RJ, (2016).

Fonte: Elaborado pelo autor

A construção com colmos de bambu tem baixo impacto ambiental pois esta planta produz material lignocelulósico com resistência mecânica adequada para muitos usos na construção civil, como mostraram Berndsen et al (2014), Carbonari et al, (2017), e precisa de pouca energia para ser produzida. É uma matéria prima de relativamente baixo custo, de fácil apropriação pela população e com boa disponibilidade no território nacional. Além do que, os bambuzais produzem vários serviços relevantes ao meio ambiente tais como: proteção do solo, da água e da fauna, contenção de encostas, recuperação de áreas degradadas, entre outros.

Para maior durabilidade das estruturas de bambu, o material precisa ser tratado, e o bambu deve ficar protegido da umidade e da luz solar como indicam, Janssen (1995) e Hidalgo (2003). De um modo geral, as técnicas mais baratas e eficientes tanto para a construção como para a preservação das estruturas e habitações de bambu, são desconhecidas pela maioria da população brasileira. Na Figura 3 é mostrada uma possibilidade de tratamento de colmos, esteiras, ripas e peças prontas de bambu, através da submersão em tanque com solução de sais preservantes como os de boro e de cobre.

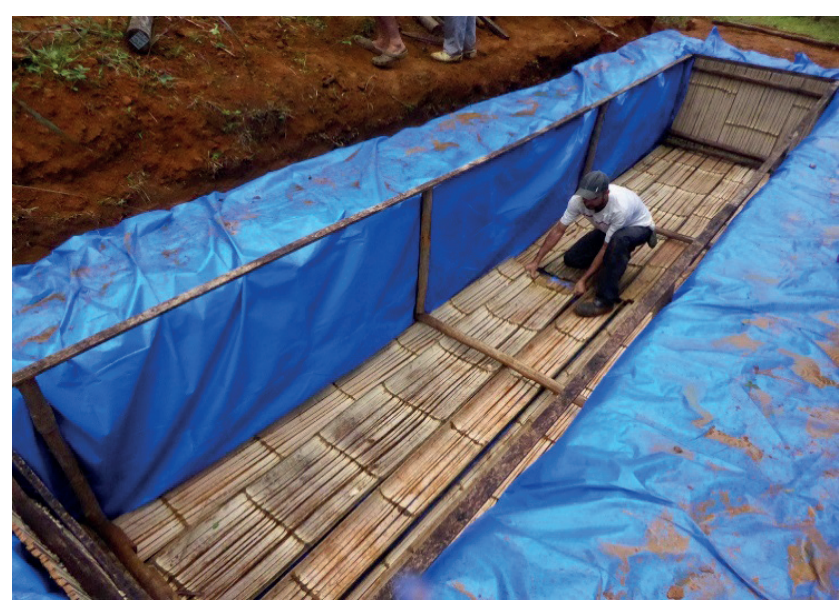

Figura 3: Estufa de D. asper e Guadua angustifólia na comunidade Hare Krsna de Goura Vrindavana, Paraty- RJ, (2016).

Fonte: Elaborado pelo autor

O uso do bambu na construção civil, permite reduzir o uso de materiais mais agressivos ao meio ambiente, agregar valor e beleza à edificação arquitetônica, no entanto, exige mão de obra capacitada e especializada. Muitos materiais de bambu usados na construção civil como ripas, tubulações, calhas, colunas e vigas tubulares, entre outros, podem ser produzidas pelo próprio trabalhador no local da obra, desde que haja disponibilidade da matéria prima.

A forma mais simples de processamento de colmos de bambu é manual. Com o uso de técnicas e ferramentas manuais é possível produzir variados produtos de interesse para a arquitetura e construção civil. No entanto, estes produtos processados manualmente apresentam problemas como a grande variabilidade dimensional. Uma das formas de contornar este problema é o desenvolvimento de produtos modulares de bambu e madeira. 


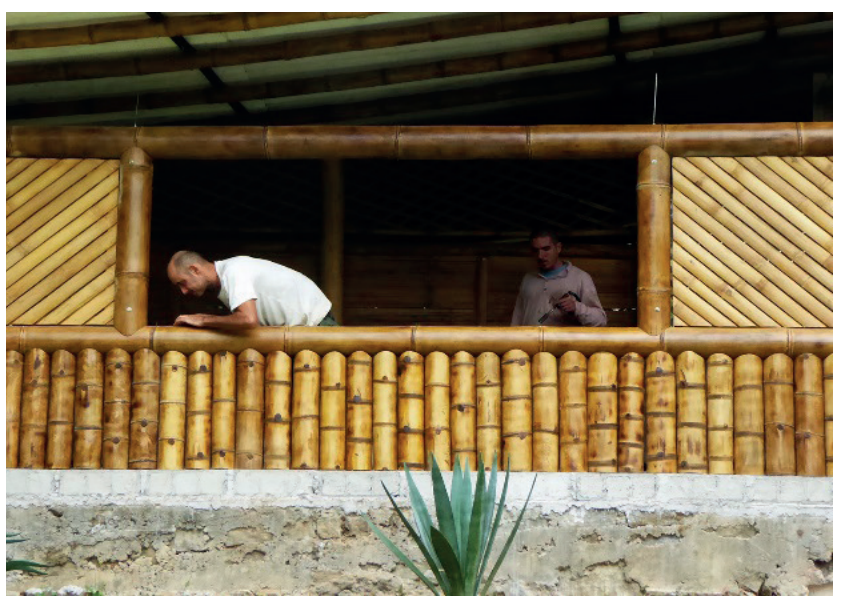

Figura 4: Trabalhadores montando uma parede de bambu, Paraty - RJ (2016).

Fonte: Elaborado pelo autor

\subsection{Objetivos do trabalho}

- Produzir deques modulares de bambu e madeira, com dimensão de $(40 \times 40 \mathrm{~cm})$.

- Projetar, produzir e analisar os tempos de fabricação dos deques modulares de bambu e madeira, que podem ser utilizados na construção de uma variedade grande de produtos tais como: paredes, pisos, tetos, móveis, portas, janelas, escadas, etc.

- Projetar e construir uma parede de 4 por 2,8 metros, composto por 70 elementos modulares, para mostrar algumas possibilidades de montagem.

- Projetar e construir móveis simples do tipo banquetas e estantes.

- Fazer a análise do fluxo de processo e a cronoanálise das etapas para levantar os tempos de fabricação de um elemento modular do tipo deque de bambu e madeira.

\subsection{Justificativa}

A cadeia produtiva do bambu no Brasil ainda é incipiente, mas tem um enorme potencial, vem sendo incentivada e tende a crescer cada vez mais.

Projetar e fabricar produtos de bambu de baixo custo ou não, agregados ou não a outros tipos de materiais tais como madeiras, metais e polímeros, mesmo que na forma de protótipos experimentais, é uma maneira efetiva que o pesquisador e a universidade tem de fomentar o desenvolvimento de novos produtos e possíveis arranjos produtivos que podem se disseminar gerando renda e desenvolvimento tecnológico, econômico e social pelo país.

\section{REVISÃO BIBLIOGRÁFICA}

\subsection{O uso de colmos de bambu na construção civil}

O colmo do bambu é composto de material lignocelulósico e apresenta, de um modo geral, propriedades e características físicas e químicas muito semelhantes a madeira proveniente das árvores, Ostapiv et al (2008). No entanto, diferente das árvores, os colmos de bambu são elementos vegetais tubulares e seu uso na construção civil ou na indústria, traz vários desafios tecnológicos a serem superados, tais como: tratamentos, processamentos e uniões dos mesmos.

$\mathrm{Na}$ Figura 5 é mostrado um experimento onde a união entre os colmos cilíndricos de Bambusa tuldoides foi feita com embalagens reutilizadas de PET (polietileno tereftalato). Os colmos foram revestidos com pedaços cilíndricos de garrafas PET que foram então termoformadas, formando um painel que pode ser usado de diversas maneiras na construção civil de baixo custo.

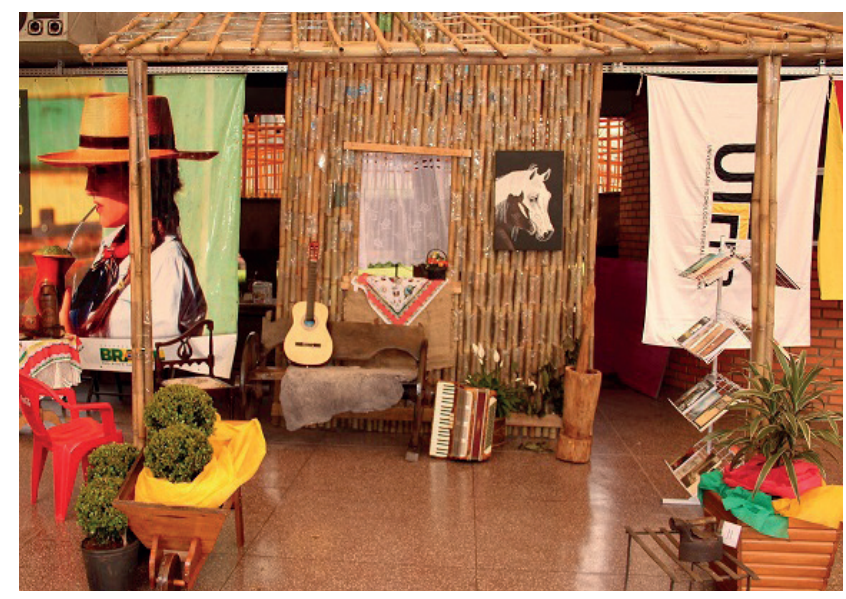

Figura 5: Parede de colmos de bambu tuldoides unidos com embalagens PET termoformadas, UTFPR-PB (2015).

Fonte: Elaborado pelo autor

\subsection{O uso de ripas de bambu}

Já o uso de elementos processados gerados a partir dos colmos de bambu, tais como ripas, lâminas, lascas, cavacos e pós, trazem novos tipos de desafios, especialmente no processamento dos colmos de bambu, como mostrou Salamon (2009). Destes elementos processados, a ripa de bambu é seguramente o elemento mais simples de ser obtido e também de ser usado, tanto na lógica artesanal como na semi industrial. A partir das ripas é possível a produção de uma variedade de produtos industrializados de alto valor agregado como tábuas, vigas, pisos, painéis laminados, entre outros, Ostapiv, (2007 e 2011).

Neste trabalho foi analisado a produção de ripas de bambu, através do processamento manual mais simples 
possível dos colmos. Estas ripas produzidas foram então usadas na construção de deques modulares básicos de bambu e madeira, como o mostrado na Figura 6.

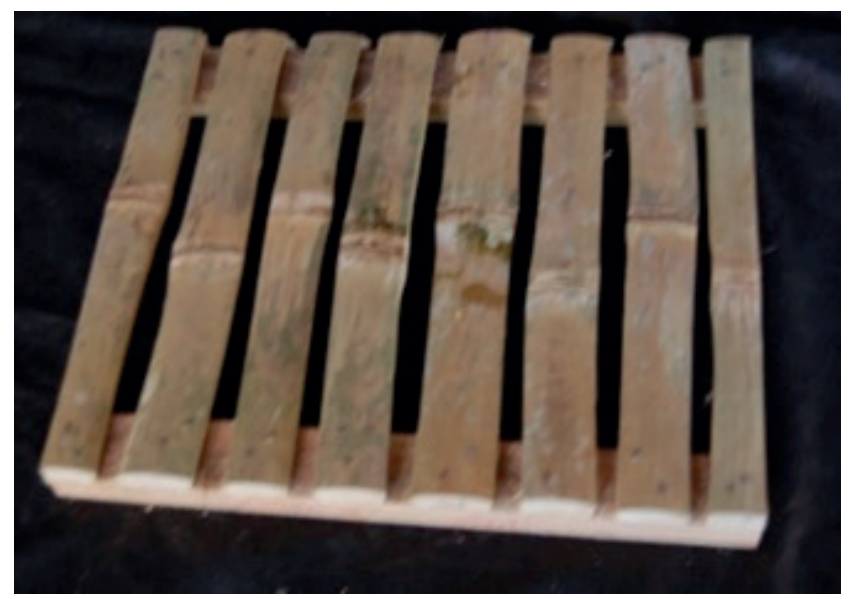

Figura 6: Deque modular de bambu ripado e madeira. Fonte: Elaborado pelo autor

\subsection{Processamento}

O fluxograma de produção, as atividades produtivas e os tempos de processamento são informações importantes, pois além de comporem parte fundamental do custo final do produto, servem para o planejamento produtivo, como argumentam Silva e Coimbra (1980).

Existem várias possibilidades para a produção manual das ripas de bambu. Basicamente um pedaço de um colmo de bambu é cortado longitudinalmente usando algum tipo de ferramenta cortante como facão, mostrado na Figura 6, ou uma faca múltipla chamada faca estrela, mostrada na Figura 7, ou ainda usando equipamentos como a serra circular.

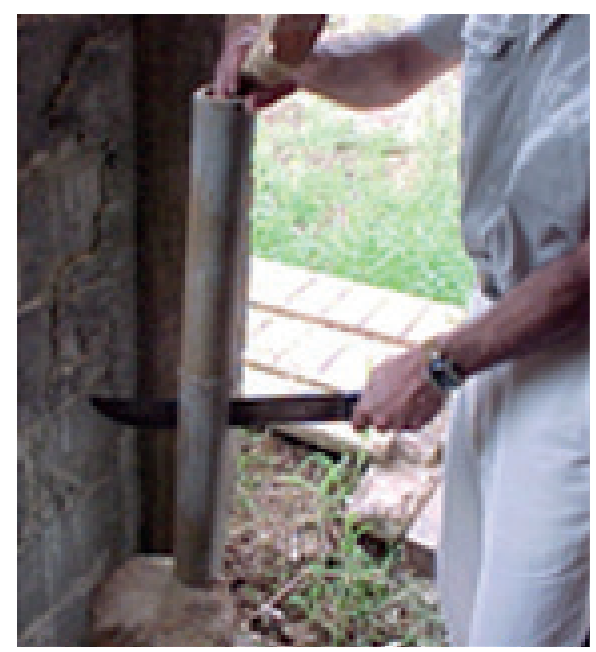

Figura 7: Corte de colmo de bambu ao meio com facão e macete. Fonte: Elaborado pelo autor

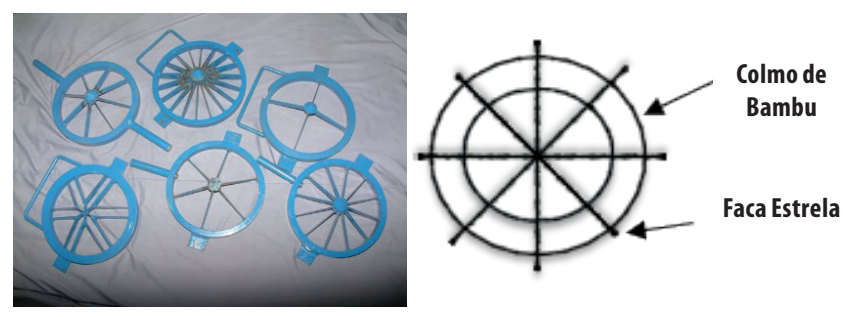

Figura 8: Conjunto de facas estrela, esquema de corte com 8 lâminas e demonstração do uso da ferramenta.

Fonte: Elaborado pelo autor

O uso de facas estrelas, comparativamente ao facão, reduz o tempo para produção das ripas de bambu e diminui a variabilidade da largura das tábuas produzidas. Neste trabalho, no entanto, foi usado apenas o facão, para mostrar que é possível a praticamente qualquer trabalhador produzir ripas de bambu de maneira simples e acessível.

\subsection{Tempos de produção}

A cronometragem e a padronização dos tempos e métodos já eram estudadas por Taylor no início da produção industrial seriada, no modelo chamado de Fordismo. Como explica Barnes (1977), os tempos de produção são dados fundamentais tanto para a composição do custo final de produtos seriados bem como para análise e melhoria do processo de produção destes produtos. Estas técnicas de análise produtiva são muito úteis e permanecem válidas na busca da racionalização dos tempos e movimentos produtivos, permitindo o treinamento de trabalhadores em arranjos mais adequados e eficientes. Na análise dos movimentos repetitivos, são incorporadas considerações sobre a fadiga, o ritmo e a influência do meio externo sobre o trabalhador. Atualmente muitos locais de trabalho filmam o trabalhador no posto de trabalho para então analisar os tempos e movimentos que o trabalhador realiza.

\section{METODOLOGIA E MATERIAIS}

Para estudo e produção dos deques modulares de bambu e madeira, foram usados colmos maduros da espécie Dendrocalamus asper. Não foram adotados pré tratamentos nos colmos colhidos.

$\mathrm{Na}$ floresta de bambu foram feitas as seguintes etapas: identificação visual dos colmos maduros; colheita dos colmos; limpeza dos galhos dos colmos; corte dos colmos com 3,5m de comprimento para transporte usando moto serra elétrica.

O processamento dos colmos para obtenção das ripas de bambu, foi feito de forma manual, as etapas produtivas são mostradas na Tabela 01. Foram fabricadas aproximadamente 640 ripas de bambu ou 80 lotes. 
Foi feita a cronoanálise da produção de 320 ripas produzidas a partir de 40 peças de colmos de bambu e então foram calculados os tempos produtivos padrão para a obtenção das ripas de bambu. Foram usadas 20 peças da região da base e 20 da região do meio dos colmos de bambu. No trabalho de processamento das ripas e na produção dos módulos de bambu e madeira, foram considerados: ritmo e esforço normais e um trabalhador com habilidade normal.

O lote de colmos usados neste estudo já estava desgalhado, esta atividade e outras atividades prévias feitas no bambuzal não foram analisadas. Os colmos foram divididos em região da base e região do meio e destas regiões foram extraídas peças com comprimento de $2 \mathrm{~m}$ cada, ou seja, no total foram usados 10 colmos para realizar este ensaio produtivo.

Os quadros de madeira usados como base para a fixação das ripas de bambu foram feitos de ripas de Araucaria angustifolia com seção de $(2,5 \times 5 \mathrm{~cm})$. As etapas e tempos de construção dos quadros de madeira são mostradas na Tabela 02.

Foram usados parafusos auto atarrachantes de $4,5 \mathrm{~mm}$ de diâmetro, $5 \mathrm{~cm}$ de comprimento e cabeça chata, usados para fixar o quadro de madeira da base e pregos para fixar as ripas de bambu. Todas as ripas de bambu foram furadas antes de serem pregadas, para evitar fendilhamento longitudinal. As etapas e tempos de montagem final dos módulos de bambu e madeira são mostradas na Tabela 03.

Os elementos modulares de bambu produzidos foram então aparafusados entre si, para formar diferentes tipos de produtos como móveis Figuras 9 e 10 ou paredes, Figuras 10 e 11.

\section{RESULTADOS E APLICAÇÕES}

Fade et al, (2008) argumentam que o deque modular de madeira e bambu é um elemento padronizado e intercambiável, assim como um tijolo ou uma peça de um jogo de montar, podendo ser usado em diversos tipos de arranjos construtivos. Nas Figuras 9, 10 e 11 são mostrados exemplos do uso destes deques.
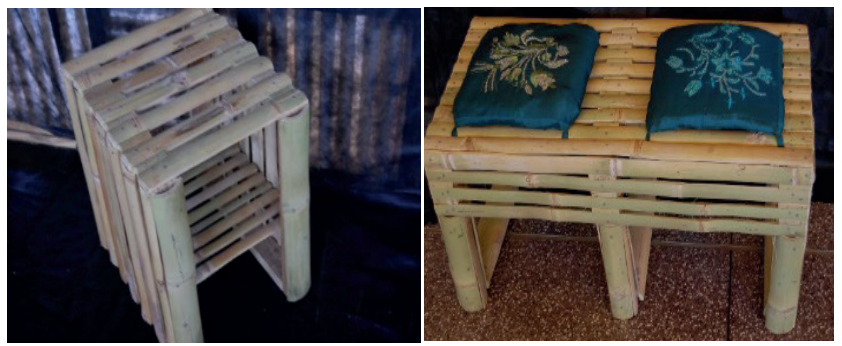

Figura 9: Móveis usando módulos de um e dois volumes. Fonte: Elaborado pelo autor.

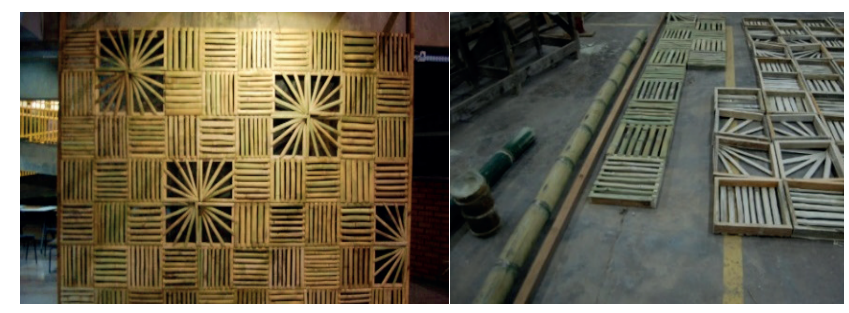

Figura 10: Painel com elementos modulares de bambu e madeira. Fonte: Elaborado pelo autor.

Na produção dos painéis da Figura 10 foram usados 70 elementos modulares e aproximadamente 560 ripas de bambu. O tempo total para a produção destes elementos modulares foi de $43,4 \mathrm{~h}$ e para montagem final do painel $16 \mathrm{~h}$ totalizando $59,4 \mathrm{~h}$ de trabalho.

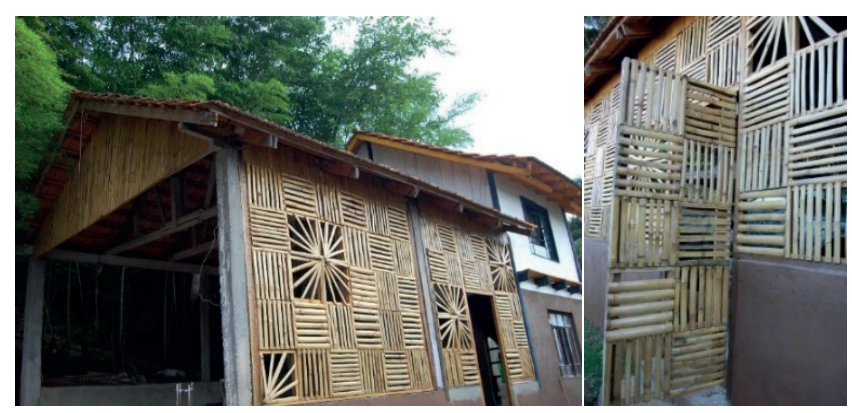

Figura 11: Elementos modulares nas paredes e portas de uma garagem Fonte: Elaborado pelo autor.

O processo produtivo dos módulos de bambu e madeira são mostrados nas Tabelas 1, 2, 3 e 4 de forma sequencial. Cada atividade produtiva teve seu tempo padrão cronometrado e os resultados aparecem nas mesmas tabelas.

Foram encontradas diferenças significativas no tempo padrão para a produção de ripas da região da base em relação ao meio dos colmos de Dendrocalamus asper, mostrados nas Tabelas 1 e 2 . A produção de ripas a partir de peças da base do colmo são mais difíceis de serem produzidas pois exigem maior esforço de corte devido a maior espessura da parede do bambu nesta região. Assim os tempos produtivos padrão são maiores em relação as ripas produzidas a partir da região central dos colmos.

Outra questão importante a ser considerada é o teor de umidade (t.u.) dos colmos a serem processados. Colmos verdes são mais fáceis de serem cortados ao passo que colmos secos, a aproximadamente $15 \%$ de t.u. são mais difíceis, pois exigem maior esforço de corte e desgastam mais as ferramentas, que perdem o fio mais facilmente. Os colmos usados neste trabalho estavam todos secos nas condições ambiente.

A produção dos elementos modulares de bambu e madeira foram feitas de forma semi artesanal, ou seja, foram utilizadas poucas máquinas e o processamento 
do bambu foi feito de forma manual. Assim, os tempos padrão são grandes, no entanto, se forem introduzidos novos equipamentos a produtividade aumentará significativamente. Como os tempos produtivos manuais são elevados, o custo da mão de obra também é elevado.

A região da base dos colmos apresenta maior espessura de parede exigindo maiores esforços cortantes e, portanto, maiores tempos de processamento manual, aproximadamente $27 \%$ maiores, como mostra a Tabela 2. Além disso, a região da base dos colmos é geralmente mais suja e tem maiores diâmetros que as regiões superiores, o que explica o maior tempo necessário para a limpeza externa destes colmos. É melhor fazer a limpeza antes de cortar o colmo em ripas, pois isto reduz o tempo de limpeza e preserva a região interna do colmo do contato com a água e possíveis contaminantes.

\subsection{Cronoanálise}

Nas Tabelas 1 e 2 os tempos obtidos são valores médios, com coeficiente de variação abaixo de $28 \%$.

\begin{tabular}{|l|l|}
\hline $\begin{array}{l}\text { Limpeza e corte longitudinal dos col- } \\
\text { mos para produção de ripas } \\
\text { Etapa 1 - (Região do meio do colmo) } \\
\text { DESCRIÇÃO DAS ATIVIDADES }\end{array}$ & $\begin{array}{l}\text { Tempo } \\
\text { padrão } \\
\text { (s) }\end{array}$ \\
\hline $\begin{array}{l}\text { 1. Selecionar os colmos verificando sua line- } \\
\text { aridade. Descartar colmos muito tortos. }\end{array}$ & 10,2 \\
\hline $\begin{array}{l}\text { 2. Limpar a área externa do colmo usando água, } \\
\text { detergente, esponja abrasiva e tecido para re- } \\
\text { tirar o excesso de água. (Peça de 2m) }\end{array}$ & 147,2 \\
\hline $\begin{array}{l}\text { 3. Cortar os colmos em peças de 45 cm de } \\
\text { comprimento usando serra manual. }\end{array}$ & 183,3 \\
\hline $\begin{array}{l}\text { 4. Com um facão e um macete de madeira ou mar- } \\
\text { telo de borracha, dividir o colmo longitudinalmente } \\
\text { ao meio. Usar o macete para bater no facão. }\end{array}$ & 55,3 \\
\hline $\begin{array}{l}\text { 5. Repetir duas vezes a operação, dividin- } \\
\text { do os dois meio colmos novamente ao meio, } \\
\text { produzindo 4 ripas de (1/4) do diâmetro. }\end{array}$ & 23 \\
\hline $\begin{array}{l}\text { 6. Repetir a operação quatro vezes, dividindo } \\
\text { as ripas de 1/4 de colmo novamente ao meio, } \\
\text { produzindo 8 ripas de (1/8) do diâmetro. }\end{array}$ & 48,2 \\
\hline $\begin{array}{l}\text { 7. Com o facão, retirar o diafragma inter- } \\
\text { no (na região do nó) das 8 ripas. }\end{array}$ & 184 \\
\hline $\begin{array}{l}\text { 8. Com o facão, retirar as rebarbas la- } \\
\text { terais das 8 ripas produzidas. }\end{array}$ & 798,6 \\
\hline TEMPO PRODUTIVO TOTAL & 1023,2 \\
\hline TEMPO IMPRODUTIVO TOTAL & \\
\hline TEMPO PADRÃO & 18,6 \\
\hline
\end{tabular}

Tabela 1: Tempos e atividades para a produção de 8 ripas de bambu da região do meio do colmo por faqueamento.

Fonte: Elaborado pelo autor

\begin{tabular}{|l|l|}
\hline $\begin{array}{l}\text { Limpeza e corte longitudinal dos col- } \\
\text { mos para produção de ripas } \\
\text { Etapa 1 - (Região da base do colmo) } \\
\text { DESCRIÇÃO DAS ATIVIDADES }\end{array}$ & $\begin{array}{l}\text { Tempo } \\
\text { padrão } \\
\text { (s) }\end{array}$ \\
\hline $\begin{array}{l}\text { 1. Selecionar os colmos verificando sua line- } \\
\text { aridade. Descartar colmos muito tortos. }\end{array}$ & 19,8 \\
\hline $\begin{array}{l}\text { 2. Limpar a área externa do colmo usando água, } \\
\text { detergente, esponja abrasiva e tecido para re- } \\
\text { tirar o excesso de água. (Peça de 2m) }\end{array}$ & 205,3 \\
\hline $\begin{array}{l}\text { 3. Cortar os colmos em peças de 45 cm de } \\
\text { comprimento usando serra manual. }\end{array}$ & 283,5 \\
\hline $\begin{array}{l}\text { 4. Com um facão e um macete de madeira ou mar- } \\
\text { telo de borracha, dividir o colmo longitudinalmente } \\
\text { ao meio. Usar o macete para bater no facão. }\end{array}$ & 100,2 \\
\hline $\begin{array}{l}\text { 5. Repetir duas vezes a operação, dividin- } \\
\text { do os dois meio colmos novamente ao meio, } \\
\text { produzindo 4 ripas de (1/4) do diâmetro. }\end{array}$ & 59,5 \\
\hline $\begin{array}{l}\text { 6. Repetir a operação quatro vezes, dividindo } \\
\text { as ripas de 1/4 de colmo novamente ao meio, } \\
\text { produzindo 8 ripas de (1/8) do diâmetro. }\end{array}$ & 92 \\
\hline $\begin{array}{l}\text { 7. Com o facão, retirar o diafragma inter- } \\
\text { no (na região do nó) das 8 ripas. }\end{array}$ & 185,6 \\
\hline $\begin{array}{l}\text { 8. Com o facão, retirar as rebarbas la- } \\
\text { terais das 8 ripas produzidas. }\end{array}$ & 257,7 \\
\hline TEMPO PRODUTIVO TOTAL & 1203,6 \\
\hline TEMPO IMPRODUTIVO TOTAL & 212,4 \\
\hline TEMPO PADRÃO & 1416 \\
\hline
\end{tabular}

Tabela 2: Tempos e atividades para a produção de 8 ripas de bambu da região da base do colmo por faqueament.

Fonte: Elaborado pelo autor

Nesta etapa são descritas as atividades necessárias para a produção do quadro de madeira do deque, mostrado na Figura 12, na qual serão colocadas as ripas de bambu obtidas na etapa 1 .

\begin{tabular}{|l|l|}
\hline $\begin{array}{l}\text { Produção dos quadros de madeira } \\
\text { Etapa 2 - DESCRIÇÃo DAS ATIVIDADES }\end{array}$ & $\begin{array}{l}\text { Tempo } \\
\text { padrão } \\
\text { (s) }\end{array}$ \\
\hline $\begin{array}{l}\text { 1. Posicionar e cortar lote de 8 peças de madei- } \\
\text { ra com } 35 \text { cm de comprimento, em ângulo reto, } \\
\text { na serra policorte. Usar ripa inicial de 3m. } \\
\text { Esta atividade pode ser feita na madeireira. }\end{array}$ & $\begin{array}{l}19,6 \\
2 p c ̧\end{array}$ \\
\hline $\begin{array}{l}\text { 2. Posicionar e cortar lote de 8 peças de ma- } \\
\text { deira com } 40 \text { cm de comprimento, em ân- } \\
\text { gulo reto. Usar ripa inicial de 3,5m. } \\
\text { Esta atividade também pode ser feita na madeireira. }\end{array}$ & $\begin{array}{l}20,8 \\
2 p c ̧\end{array}$ \\
\hline $\begin{array}{l}\text { 3. Posicionar lote com } 8 \text { ripas de } 40 \text { cm no gaba- } \\
\text { rito para furação. É necessário usar um gabarito, } \\
\text { caso contrário este tempo aumenta muito. }\end{array}$ & 14,2 \\
\hline $\begin{array}{l}\text { 4. Marcar os linhas de centro dos furos devem } \\
\text { ficar a 1,25 cm das extremidades das ripas. }\end{array}$ & 41 \\
\hline
\end{tabular}




\begin{tabular}{|l|l|}
\hline $\begin{array}{l}\text { 5. Posicionar e fazer } 4 \text { furos de diâmetro } \\
\text { 4,5mm, dois em cada extremidade das ri- } \\
\text { pas de } 40 \mathrm{~cm} \text { conforme figura } 11 .\end{array}$ & $\begin{array}{l}94,2 \\
2 \mathrm{pç}\end{array}$ \\
\hline $\begin{array}{l}\text { 6. Pré-montar o quadro com uma peça de } \\
\begin{array}{l}40 \text { sobre duas de } 35 \mathrm{~cm} \text { fixadas vertical- } \\
\text { mente no gabarito, conforme figura. }\end{array}\end{array}$ & 35,3 \\
\hline $\begin{array}{l}\text { 7. Parafusar o conjunto, usar 2 para- } \\
\text { fusos em cada extremidade.. }\end{array}$ & 105 \\
\hline $\begin{array}{l}\text { 8. Retirar o conjunto do gabarito, inverter, posicio- } \\
\text { nar outra peça de } 40 \text { cm para fechar o conjunto. } \\
\text { Parafusar, verificando o esquadro. Figura 11 }\end{array}$ & 112,6 \\
\hline TEMPO PRODUTIVO TOTAL & 442,7 \\
\hline TEMPO IMPRODUTIVO TOTAL & 190,3 \\
\hline TEMPO PADRÃO & 633 \\
\hline
\end{tabular}

Tabela 3: Tempos e atividades para a produção de 8 ripas de bambu da região da base do colmo por faqueament.

Fonte: Elaborado pelo autor

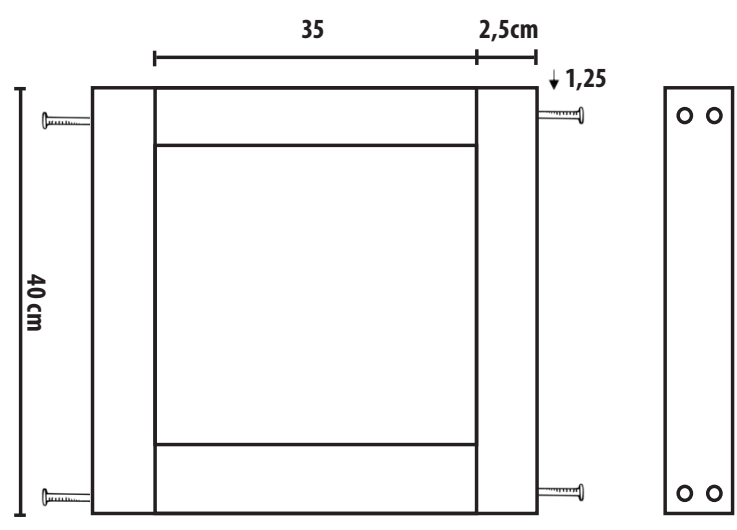

Figura 12: Quadro de madeira do deque modular .

Fonte: Elaborado pelo autor

$\mathrm{Na}$ etapa 3 o tempo foi dividido por 4 pois um pedaço de colmo de $2 \mathrm{~m}$ é dividido em 4 peças e uma peça destas é suficiente para a produção de 8 ripas que compõe um deque modular.

\begin{tabular}{|l|l|}
\hline $\begin{array}{l}\text { Produção dos elementos modu- } \\
\text { lares de bambu/madeira } \\
\text { Etapa 3 - DESCRIÇÃO DAS ATIVIDADES }\end{array}$ & $\begin{array}{l}\text { Tempo } \\
\text { padrão } \\
\text { (s) }\end{array}$ \\
\hline $\begin{array}{l}\text { 1. Com a base de madeira montada, colocar } \\
\text { as ripas de bambu distribuindo-as de manei- } \\
\text { ra uniforme, verificando posição dos nós. }\end{array}$ & 26,8 \\
\hline $\begin{array}{l}\text { 2. Fixar as ripas de bambu com aces- } \\
\text { sórios para fazer a furação. }\end{array}$ & 35,5 \\
\hline $\begin{array}{l}\text { 3. Fazer um furo em cada extremidade das ri- } \\
\text { pas de bambu para serem pregadas. Pode ser } \\
\text { usado um prego sem cabeça como broca. }\end{array}$ & 108,8 \\
\hline
\end{tabular}

\begin{tabular}{|l|l|}
\hline $\begin{array}{l}\text { 4. Mantendo as ripas posicionadas, pregar as ripas } \\
\text { de bambu no quadro de madeira da Figura 12. }\end{array}$ & 84,4 \\
\hline $\begin{array}{l}\text { 5. Cortar o excesso de material das ripas de bam- } \\
\text { bu que ultrapassem os limites do as bordas do } \\
\text { módulo, usando serra manual. Figura 13. }\end{array}$ & 133,5 \\
\hline TEMPO PRODUTIVO TOTAL & 389 \\
\hline TEMPO IMPRODUTIVO TOTAL & 187,1 \\
\hline TEMPO PADRÃO & 576,1 \\
\hline
\end{tabular}

Tabela 4: Tempos e atividades para montagem dos módulos de bambu/madeira. Fonte: Elaborado pelo autor

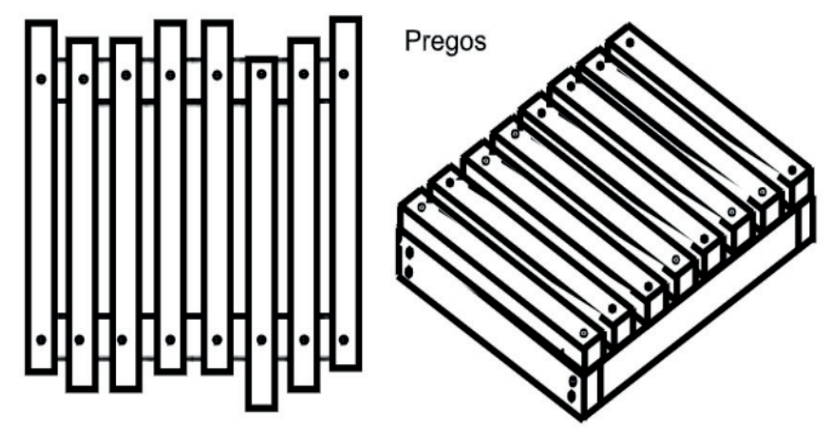

Figura 13: Quadro com sobre material a ser cortado e deque modular finalizado Fonte: Elaborado pelo autor

\begin{tabular}{|l|l|l|}
\hline $\begin{array}{l}\text { Elemento modular } \\
\text { bambu/ madeira }\end{array}$ & $\begin{array}{l}\text { Região do } \\
\text { meio do } \\
\text { colmo }\end{array}$ & $\begin{array}{l}\text { Região da } \\
\text { base do } \\
\text { colmo }\end{array}$ \\
\hline Tempo padrão total & $37,2 \mathrm{~min}$ & $43,7 \mathrm{~min}$ \\
\hline Tempos produtivos total & $27,2 \mathrm{~min}$ & $33,9 \mathrm{~min}$ \\
\hline Tempos improdutivos total & $10 \mathrm{~min}$ & $9,8 \mathrm{~min}$ \\
\hline
\end{tabular}

Tabela 5: Tempos padrão total para montagem dos deques modulares de bambu e madeira Fonte: Elaborado pelo autor

Os tempos improdutivos envolvem várias atividades como: preparação do local de trabalho, transporte e posicionamento de materiais, ferramentas, gabaritos, instrumentos de medida, limpeza do local de trabalho, ajuste de máquinas, afiação de ferramentas, etc.

\subsection{Proposta de arranjo produtivo}

Os tempos padrão obtidos na produção dos módulos de bambu e madeira, de maneira quase que artesanal, podem ser reduzidos significativamente caso seja feito simplesmente uma organização produtiva mais adequada como a proposta na Figura 14. Um arranjo produtivo racionalizado permite reduzir os tempos improdutivos. Outras melhorias podem ser indicadas como o uso de máquinas de corte tipo serra circular e gabaritos que permitem a redução dos tempos produtivos 


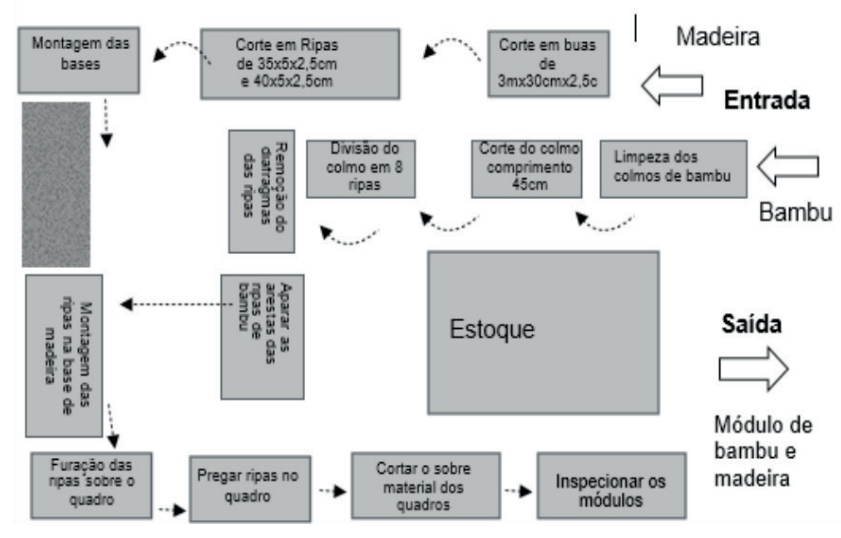

Figura 14: Fluxograma earranjo produtivo para produção deelementosmodulares de bambuemadeira. Fonte: Elaborado pelo autor

O fluxograma indica uma sequência lógica para a produção dos elementos modulares de bambu e madeira, que permitiria a produção destes elementos de forma seriada.

\section{REFERÊNCIAS}

BARNES, R. M.; “Estudo de movimentos e de tempos - Projeto e medida do trabalho". Ed. Blucher, $1^{\text {a }}$ ed, SP, 1977.

BERNDSEN, R.S.; KLITZKE, R.J.; BATISTA, D.C.; NASCIMENTO, E.M,; OSTAP
OSTAPIV, F.; “Análise e melhoria do processo produtivo de tábuas de bambu (Phyllostachys pubescens) com foco em pisos". 111f. Dissertação (Mestrado em Engenharia) - Programa de Pós-graduação em Engenharia Mecânica e de Materiais, Universidade Tecnológica Federal do Paraná, Curitiba, 2007.

OSTAPIV, F.; SALAMON, C.; GONÇALVES, M.T.T.; “Estrutura da Madeira de Bambu mossô (Phyllostachys pubescens) e seus usos industriais - perspectivas para o mercado brasileiro". XI Encontro Brasileiro de Madeiras e Estruturas em Madeira - EBRAMEM, Londrina, PR, julho 2008.

OSTAPIV, F;; “Resistência mecânica do material compósito: madeira de eucalipto-lâmina de bambu". 148f. Tese de Doutorado. Guaratinguetá: Faculdade de Engenharia do Campus de Guaratinguetá, Universidade Estadual Paulista, 2011.

OSTAPIV, F.; "Produção e uso de materiais compósitos bambu-PET na construção civil popular" Capítulo de: Bambus no Brasil, da Biologia à

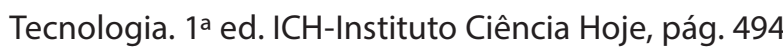
a 510, RJ, 2017. tance of moso bamboo (Phyllostachys pubescens) Part 2: axial tensile strength, hardness and wear resistance" FLORESTA, v.44, n³, p. $505-514$, jul./set. 2014 - Curitiba PR.

CARBONARI, G.; SILVA Jr, N. M.; PEDROSA, N.H.; ABE, C.H.; SCHOLTZ, M.F.; ACOSTA. C.C.V.; CARBONARI, L.T.; "Bambu - $O$ aço vegetal" Mix Sustentável, Edição 5, v.3, nº , Florianópolis, SC, 2017.

FADE, B.C.; OSTAPIV, F. SALAMON, C. “Bambu como alternativa ao uso da madeira na produção de decks para a construção civil - estudo de caso em uma Comunidade caiçara no município de Guaraqueçaba PR". XI EBRAMEM Encontro Brasileiro em Madeira e Estruturas de Madeira, Londrina -julho 2008.

HIDALGO, L.O.; "Bamboo - The gift of the gods" D' vinni Ltda, Bogota - Colombia, 2003.

JANSSEN, J.; “Building with bamboo. A handbook”. Warwickshire: ITDG Publishing, 1995.
SALAMON. C.; “Ensaios para viabilizar a laminação do bambu Dendrocalamus giganteus em operações de torneamento sem centros". $113 \mathrm{f}$. Tese (Doutorado em Engenharia Mecânica) - Faculdade de Engenharia do Campus de Guaratinguetá Universidade Estadual Paulista, Guaratinguetá, 2009.

SILVA, J.C.B.V.; LIMA, N.; OLIVEIRA. V.M.; “Estufa ecológica. Uso do bambu em bioconstruções". Manual Referências Agroecológicas. CPRA, 32p - Curitiba, 2011.

SILVA, A.V.; COIMBRA, R.R.C.; “Manual de tempos e métodos". São Paulo: Hemus, 1980. 


\section{AUTORES}

ORICID: https://orcid.org/0000-0001-5397-1968

FABIANO OSTAPIV, Dr. | Universidade Tecnológica Federal do Paraná | Engenharia Mecânica | Pato Branco, PR | Correspondência para: Universidade Tecnológica Federal do Paraná, Campus Pato Branco., Rua Via do Conhecimento, Fraron, Pato Branco - PR, 85503390 | E-mail: fabianoosapiv@utfpr.edu.br

ORCID: https://orcid.org/0000-0001-9958-6491

CELSO SALAMON, Dr. | Universidade Tecnológica Federal do Paraná | Engenharia Mecânica | Curitiba, PR | Correspondência para: Universidade Tecnológica Federal do Paraná, Damec, Avenida Sete de Setembro, 3165, Rebouças, Curitiba - PR, 80230-901 | E-mail: salamon@ utfpr.edu.br

\section{COMO CITAR ESTE ARTIGO}

OSTAPIV, Fabiano; SALAMON, Celso. Produção e uso de deques modulares de bambu e madeira. MIX Sustentável, [S.I.], v. 5, n. 1, p. 43-51, mar-jun. 2019. ISSN 24473073. Disponível em:<http://www.nexos. ufsc.br/index.php/mixsustentavel>. Acesso em: dia mês. ano. doi:https://doi.org/10.29183/2447-3073. MIX2019.v5.n1.43-51. 